\title{
Multiple roles and therapeutic implications of Akt signaling in cancer
}

\author{
This article was published in the following Dove Press journal: \\ OncoTargets and Therapy \\ 3 June 2009 \\ Number of times this article has been viewed
}

\author{
Emiliano Calvo' \\ Victoria Bolós ${ }^{2}$ \\ Enrique Grande ${ }^{2}$ \\ 'Centro Integral Oncológico Clara \\ Campal (CIOCC), Madrid. Spain; \\ 2Pfizer Oncology, Alcobendas-Madrid, \\ Spain
}

Correspondence: $M$ Victoria Bolós Pfizer Oncology,Avda. de Europa 20B, Alcobendas-Madrid, ZIP 28108, Spain Tel +34 9l 4909660 $\mathrm{Fax}+34914909751$

Email mariavictoria.bolos@pfizer.com

\begin{abstract}
The prominence of the PI3K-Akt signaling pathway in several tumors indicates a relationship with tumor grade and proliferation. Critical cellular processes are driven through this pathway. More detailed knowledge of the pathogenesis of tumors would enable us to design targeted drugs to block both membrane tyrosine kinase receptors and the intracellular kinases involved in the transmission of the signal. The newly approved molecular inhibitors sunitinib (an inhibitor of vascular endothelial growth factor receptor, platelet-derived growth factor receptor, and other tyrosine kinase receptors), sorafenib (a serine-threonine kinase inhibitor that acts against B-Raf) and temsirolimus (an mTOR inhibitor) shown clinical activity in advanced kidney cancer. Chronic myeloid leukemia has changed its natural history thanks to imatinib and dasatinib, both of which inhibit the intracellular bcr/abl protein derived from the alteration in the Philadelphia chromosome. Intracellular pathways are still important in cancer development and their blockade directly affects outcome. Cross-talk has been observed but is not well understood. Vertical and horizontal pathway blockade are promising anticancer strategies. Indeed, preclinical and early clinical data suggest that combining superficial and intracellular blocking agents can synergize and leverage single-agent activity. The implication of the Akt signaling pathway in cancer is well established and has led to the development of new anticancer agents that block its activation.
\end{abstract}

Keywords: Akt, cancer, therapeutic target, Akt inhibitors

\section{Introduction}

The phosphatidylinositol 3-kinase (PI3K)-Akt pathway is situated in downstream tyrosine kinase receptors (TKRs) and regulates essential cellular functions such as proliferation, growth, and survival. ${ }^{1}$ Akt is a serine/threonine kinase that belongs to the AGC (protein kinase $\underline{\mathrm{A}}$ /protein kinase $\underline{\mathrm{G}}$ /protein kinase $\underline{\mathrm{C}}$-like) family of protein kinases. Because it shows high homology with protein kinases $\mathrm{A}$ and $\mathrm{C}$, Akt is also referred to as protein kinase $\mathrm{B}$ (PKB).

PI3K-Akt signaling is frequently altered in human cancers. ${ }^{1}$ We describe the main downstream effectors of PI3K-Akt pathway involved in its proliferative and survival responses. We also examine PI3K-Akt signaling pathway alterations associated with human cancers and their implications in the development of target-based anticancer drugs.

\section{Structure and activation of Akt kinase}

In mammals, three $A k t$ genes encode for the isoforms Akt1 ( $\mathrm{PKB} \alpha)$, Akt2 ( $\mathrm{PKB} \beta)$, and Akt3 $(\mathrm{PKB} \gamma)$, and they all have a similar structure and size. ${ }^{1}$ Akt isoforms contain 
a pleckstrin homology $(\mathrm{PH})$ domain in the N-terminus, a central catalytic domain with kinase activity, and a C-terminal regulatory domain (Figure $1 \mathrm{~A}$ ). The $\mathrm{PH}$ domain binds phosphatidylinositol-3,4,5-trisphosphate (PIP3). Akt also contains two main phosphorylation sites: Threonine308 (Thr308) in the kinase domain and Serine473 (Ser473) in the regulatory domain. $^{1}$

After binding their growth factors, TKRs can directly or indirectly, via an adaptor molecule such as IRS1, activate PI3K, a molecular complex composed of a p85 regulatory subunit and a p110 catalytic subunit. ${ }^{1}$ Phosphotyrosine residues on the cytoplasmic tail of the activated TKRs or on their associated adaptor proteins recruit PI3K complex to the membrane by binding its $\mathrm{p} 85$ regulatory subunit and removing the inhibitory effect of p85 (Figure 1B). The GTPase RAS can also directly activate PI3K through the binding to its p110 catalytic subunit. Once on the cell membrane, PI3K phosphorylates phosphatidylinositol and converts inositol 4,5 biphosphate (PIP2) into PIP3. Subsequently, Akt and the serine/threonine kinase PDK1 translocate to the membrane where they interact with PIP3 through their PH domain. This interaction promotes conformational changes in Akt, resulting in exposure of Thr308 and Ser473. Thr308 is phosphorylated by PDK1, leading to the stabilization of Akt. ${ }^{1}$ The second phosphorylation event associated with Akt activation occurs at Ser473, and is required for full activation (Figure 1B). Recently, a second protein complex with kinase activity, the mammalian target of rapamycin (mTOR)-rictor complex has been shown necessary for this Ser473 phosphorylation of Akt. ${ }^{2}$ Therefore, Akt activation implies a dual mechanism: translocation to the plasma membrane after PI3K activation followed by two phosphorylation events mediated by PDK1 and mTOR-rictor complex. This pathway is also negatively regulated at the level of PIP3 by phospholipid phosphatases, such as the phosphatase and tensin homologue PTEN. ${ }^{3}$

\section{Biological functions of Akt signaling}

Although, differences in the signaling capabilities of Akt isoforms have been established, as we review below, the biological consequences of Akt activation relevant for cancer progression are survival, proliferation, growth, angiogenesis, and metastasis (Figure 2). ${ }^{3-5}$

\section{Akt activation and cell survival}

Promotion of cell survival is the most studied function of the Akt pathway. Akt develops its anti-apoptotic role through phosphorylation of downstream substrates that control the apoptotic machinery.
Akt indirectly downregulates activation of the pro-apoptotic protein p53 by activating Mdm2 (murine double minute-2), which promotes p53 degradation. ${ }^{5}$ In response to genetic damage, p53 stimulates the expression of pro-apoptotic proteins to ensure that damaged genetic information is not passed to descending cells. Thus, tumor cells develop the ability to survive after not repairing DNA damage through activation of the PI3K-Akt pathway (Figure 2).

Additionally, Akt signaling leads to transcription of $\mathrm{NF}-\kappa \mathrm{B}$ (nuclear factor $\kappa \mathrm{B}$ ) anti-apoptotic target genes. Akt activates IKK (I $\kappa \mathrm{B}$ kinase), which induces degradation of I $\kappa B$ (the NF- $\kappa B$ inhibitor). The unmasked NF- $\kappa B$ can then enter the nucleus and activate the expression of pro-survival target genes (Figure 2).,5

Akt also restores the anti-apoptotic function of BCL-XL through inactivation of its inhibitor, BAD (Figure 2). ${ }^{3,5}$

The inactivation of the Forkhead family of transcription factors by Akt inhibits the transcription of their death target genes (Fas-ligand, Bim, and immunoglobulin-binding protein-1 [IGBP-1]; Figure 2).,5

Akt also phosphorylates p21/WAF, which increases p21 stability. Elevated p21 protein levels have been observed in various aggressive tumors linked to chemoresistance. Glioblastoma cell lines with active Akt showed higher p21 stability and were more resistant to paclitaxel. ${ }^{6}$

\section{Akt activation and proliferation}

Akt signaling can also affect proliferation by regulating proteins of the cell-cycle machinery.

Akt blocks transcription of the cell cycle inhibitor p27/ KIP1 by inactivating Forkhead transcription factors. ${ }^{3}$ It also inhibits the anti-proliferative effects of p21 and p27, thus impairing their entry into the nucleus. ${ }^{3}$

Furthermore, Akt inhibits glycogen synthase kinase-3 (GSK3), thus Akt directly prevents $\beta$-catenin degradation. Once inside the nucleus, stabilized $\beta$-catenin activates expression of pro-proliferative target genes such as cyclin D1 and $c-M y c$ (Figure 2). ${ }^{3,5}$

\section{Akt-mTOR activation and cell growth, angiogenesis, and metastasis}

The target of rapamycin (TOR) is an evolutionary conserved Ser/Thr kinase that represents the catalytic subunit of two distinct signaling complex: the mTOR-ractor complex (mTOR complex 1) and mTOR-rictor and SIN1 complex (mTOR complex 2). ${ }^{7}$ In the presence of growth-promoting signals such as nutrients and growth factors, mTOR complex 1 promotes growth by upregulation of the protein synthesis ${ }^{8}$ 
and it also induces the biogenesis of the machinery for the protein synthesis, the ribosome. ${ }^{9}$ The function of mTOR complex 2 is less well defined, it is known that is required for phosphorilation of $\mathrm{Akt}^{2}$ (Figure 3) and it is also involved in actin cytoskeleton reorganization and cell survival..$^{10} \mathrm{mTOR}$ complex 1 is inhibited by rapamycin and its derivates everolimus and tenserolimus. ${ }^{7}$ Therefore, rapamycin analogs are not able to block mTOR complex 2 effects. In fact, in response to these drugs, an increase in Akt phosphorylation is detected in tumor byopsies and tumor samples from animal models as a result of a feedback activation loop of Akt signaling through an IGF-1R-dependent mechanism. ${ }^{11-13}$

The TSC1/TSC2 (tuberous sclerosis complex) protein complex is involved in the negative regulation of the mTOR kinase (Figures 2 and 3). mTOR is activated by the GTPase Rheb which in turn is controlled by the TSC1/TSC 2 complex. As a result of growth-stimulating signals, Akt phosphorylates TSC 2 and causes the dissociation of the TSC1/TSC2 complex. This dissociation reduces the inhibitory function of the TSC1/ TSC2 complex on GTPase Rheb thus enabling the activation of the mTOR complex 1. mTOR complex 1 controls cell growth in part by phosphorylating of the kinase 70 S6K1 (S61) and the protein 4EBP-1 (4E-binding protein 1), both of them known regulators of protein synthesis (Figures 2 and 3). p70 S6K1 is activated by two phosphorylation events: phosphorylation on Ser473 by mTOR complex 2 and on Thr308 by PDK1.,14 Subsequently, phosphorylated p70 S6K1 activates the ribosomal protein $\mathrm{S} 6$ that stimulates the translation of $5^{\prime}$-TOP messenger ribonucleic acids (mRNAs). These mRNAs encode for proteins of the translation machinery, resulting in a high protein translation rate (Figures 2 and 3 ).

Besides activating p70 S6K1, mTOR controls the association of the translation initiation factor eIF-4E with its inhibitor 4EBP-1. mTOR phosphorylates the 4EBP-1 inhibitor. Thus, eIF-4E can be released from 4EBP-1 and stimulate the translation of the CAP-dependent mRNAs (Figure 3) that encode for proteins with key cellular functions such as hypoxia-inducible factor- $\alpha$ (HIF- $\alpha$ ), a transcription factor that controls the expression of approximately 30 hypoxia-regulated genes. ${ }^{7}$ These target genes include pro-angiogenic genes, such as $V E G F$ (vascular endothelial growth factor), $P D G F$ (platelet-derived growth factor), and genes that encode proteases associated with local invasion such as matrix metalloproteinase 9 (MMP9). In fact, active p70 S6K1 promotes invasion in ovarian cancer cell lines by stimulating metalloproteinase MMP9 expression. ${ }^{15}$

VEGF is considered the most potent stimulator of angiogenesis within tumors. HIF- $\alpha$ protein levels are controlled by the von Hippel-Lindau (pVHL) protein complex. ${ }^{16}$ Absence and/or inactivation of $\mathrm{pVHL}$ has been documented in many tumors, thus leading to HIF- $\alpha$ accumulation. Subsequent high VEGF expression promotes angiogenesis. ${ }^{15}$ PDGF is considered at least as important as VEGF in the stabilization and maturation of newly formed vessels. In fact, PDGF over-function may also cause tumors.

\section{Akt isoforms and specific biological functions}

It has been suggested that different Akt isoforms show different signaling capabilities. ${ }^{17}$ Different roles for Akt isoforms in the physiological response to insulin (the storage of nutrients in muscle and adipose tissues) has been already suggested. In fact, Akt2 levels increase during the differentiation of cells into insulin-responsive adipocytes, whereas the expression of Akt1 decreases in these cells. ${ }^{18,19}$ In addition, Akt2 is placed in the plasmatic membrane near the insulin-responsive GLUT4 glucose transporter whereas Akt1 is placed mainly in the cytosolic compartment. Phosphorylation of GLUT4 transporter by Akt2 has been also reported. ${ }^{20,21}$ These data suggest that Akt 2 might be involved in insulin-induced GLUT4 translocation and glucose uptake.

Additional data supporting a different role for Akt isoforms came from transgenic mice. An impairment in insulin ability to maintain normal glucose homeostasis is known as insulin resistance and predisposes to the development of type 2 diabetes, hypertension, and cardiovascular disease..$^{22}$ Accordingly, mice lacking Akt2 displayed insulin resistance and a diabetes-like syndrome. ${ }^{23}$ Mice lacking Akt1 showed normal glucose homeostasis but were small throughout life, ${ }^{24,25}$ which suggests that Akt1 may be mainly involved in control of growth and proliferation.

The knowledge of the biological functions mediated by each Akt isoform may be useful to predict the toxicities that may be associated with those inhibitors that target a specific Akt isoform or with pan-Akt inhibitors. As we review below, high grade hyperglycemia has been already observed in animal models and clinical trials with novel Akt inhibitors.

\section{Akt activation in cancer}

The PI3K-Akt pathway is often aberrantly activated in cancer (see Table 1) due to genetic and epigenetic alterations. It is also associated with poor prognosis in a variety of tumor types (pancreas, gastric, breast, tongue, glioma, non-small cell lung cancer [NSCLC], and others) and resistance to chemotherapy, radiotherapy, and/or target-based 
anticancer agents. ${ }^{26,27}$ Alterations in signaling proteins placed upstream PI3K and genetic alterations in genes that encode for proteins belonging to the pathway such as PTEN deletions and "hot-spot" mutations in $P I 3 K^{28}$ lead to an aberrant activation of this pathway and are associated with the development and progression of human cancers.

\section{Alterations upstream of PI3K-Akt}

The most common alterations upstream of PI3K-Akt include amplification/activating mutations, an increase in the expression of genes that encode for TKRs, and higher expression of genes that encode for growth factors. Activating mutations in intracellular signaling proteins placed upstream of Akt (eg, Ras) also promote the aberrant activation of Akt signaling in cancer cells, thus leading to inappropriate survival and proliferation (Figure 3).

The PI3K/Akt/mTOR and the Ras/Raf/MAPK pathways are commonly activated by TKRs, and there is a large amount of cross-talk between them (Figure 1D). ${ }^{29}$ Indeed, defects in the signaling molecules belonging to one pathway may also alter the other pathway through these interconnections. Due to this cross-talk, gain of function mutations in Ras that occur in many tumors (90\% of pancreas, $50 \%$ of colon, $50 \%$ of thyroid, $30 \%$ of lung cancers) could also be associated with an increase in Akt signalling. ${ }^{29}$ The Bcr-Abl fusion protein, generated after chromosomal translocation associated with chronic myeloid leukaemia, is also able to constitutively activate PI3K-Akt and Ras/Raf/MAPK pathways (Figure 3). ${ }^{30}$

\section{Alteration in $\mathrm{PI} 3 \mathrm{~K}$ or $\mathrm{Akt}$}

Several isoforms of the PI3K family are implicated in disease. In particular, members of the class $1 \mathrm{~A}$ PI3Ks (heterodimers with a p85 regulatory and a p110 catalytic subunit). Many tumors show activating mutations in the genes that encode for the catalytic and regulatory subunits of PI3K.,27

Akt amplification or overexpression occur at the mRNA level in various tumor cell lines and in a number of human cancers (see Table 1). Amplification in the Akt gene has been associated with poor prognosis and resistance to radiotherapy and/or chemotherapy. ${ }^{3}$ Nevertheless, activation of Akt isoforms by phosphorylation appears to be more clinically significant than Akt amplification or overexpression. ${ }^{31}$

\section{Alteration in phosphatases belonging to the pathway}

Two protein phosphatases, PTEN and SHIP (SH2 containing inositol phosphatase), negatively regulate Akt activation by blocking Akt translocation to the plasma membrane (Figure 1C).

PTEN prevents elevated levels of PIP3 by dephosphorylating its 3 ' position. Thus, PTEN leads to the blockade of Akt translocation to the plasma membrane (Figure 1C). ${ }^{3}$ PTEN is one of the most frequently mutated or deleted genes in human cancer (see Table 1), ${ }^{32}$ and its absence in tumors correlates strongly with activation of Akt. ${ }^{3}$ Pre-clinical models showed that mice with conditional tissue disruption of PTEN develop tumors in the affected tissue. ${ }^{3}$ Furthermore, PTEN loss also predicts for resistance to anticancer drugs such as the anti-HER2 (human epidermal growth factor receptor-2) agent trastuzumab. ${ }^{33}$

SHIP is another negative regulator of Akt that dephosphorylates PIP3 at the $5^{\prime}$ position (Figure 1C). Loss of SHIP can also occur in cancer cells. Peripheral $\mathrm{T}$ cells isolated from acute and chronic $\mathrm{T}$ cell leukemia/lymphoma patients showed lower levels of PTEN and SHIP, which correlates with upregulation of Akt signaling. ${ }^{34}$

In addition, Akt phosphorylation is negatively controlled by carboxyl-terminal modulating protein $(C T M P)$, which acts downstream of PTEN and SHIP, at the plasma membrane level, and binds specifically to the carboxyl-terminal regulatory domain of Akt. CTMP reduces the activity of Akt by inhibiting its phosphorylation at Ser473 and Thr308 (Figure 1C). Loss of CTMP by hypermethylation of its promoter has also been detected in glioblastoma and glioma cell lines. ${ }^{35}$

\section{Akt pathway deregulation in selected cancers}

As reviewed above, isolated or combined defects in PI3K/Akt pathway components and/or molecules in interconnected signaling cascades are associated with many cancers and lead to an increase in Akt signaling. Aberrant Akt activation mediates the signals for survival, proliferation, angiogenesis, and/or metastasis in tumor cells. Furthermore, resistance to cancer therapies is often associated with abnormal activation of this pathway.

Here, we focus on the PI3K-Akt alterations associated with specific tumors (Table 1).

\section{Renal cell carcinoma}

The most frequent histopathologic variant of renal cell carcinoma (RCC) is the clear-cell type ( $75 \%$ of cases). ${ }^{36}$

In familial and in most sporadic (40\%-60\%) clear-cell RCC tumors, $\mathrm{p} V H L$ is disrupted. ${ }^{36}$ and the PI3K-Akt-mTOR pathway plays a critical role in survival, proliferation, and angiogenesis. ${ }^{16}$ 


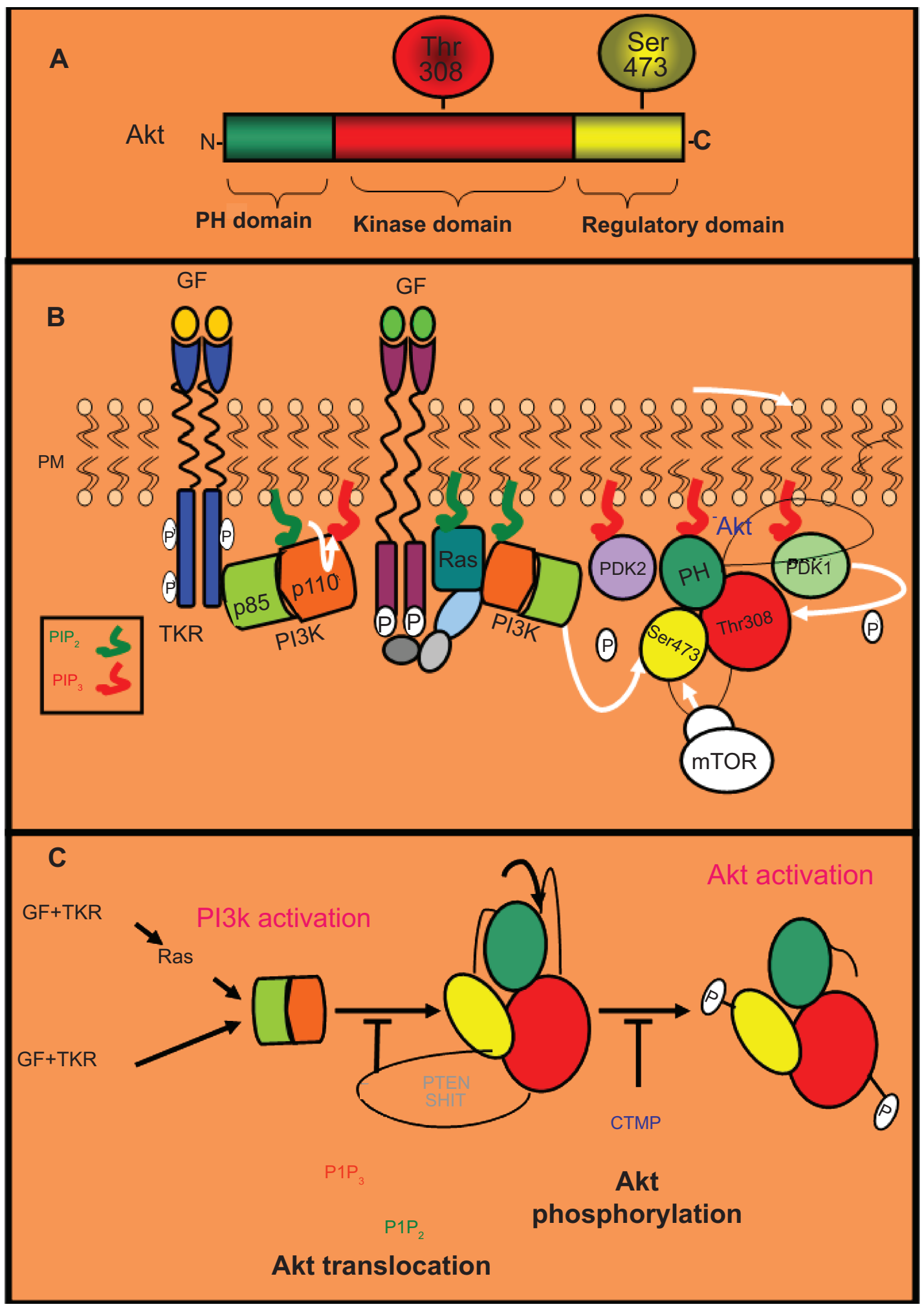

Figure I Akt structure and regulation. A) Akt structure. There are three Akt isoforms (Aktl/2/3), all of which share a similar structure and size. These isoforms contain a $\mathrm{PH}$ (pleckstrin homology) domain in the $\mathrm{N}$-terminus, a central catalytic domain with kinase activity, and a regulatory domain in the $\mathrm{C}$-terminus. The PH domain binds inositol triphosphate (PIP3).Akt also contains two main phosphorylation sites: one threonine in the kinase domain (Thr308) and one serine the regulatory domain (Ser473). B) Dual regulatory mechanism of Akt activation: translocation to the plasma membrane followed by phosphorylation. After their activation by specific growth factors (GF), tyrosine kinase receptors (TKRs) can promote the activation of the PI3K complex (p85 plus pl 10 subunits) directly or by means of the small GTPase monomeric protein Ras. Active PI3K converts inositol biphosphate (PIP2) into PIP3, which triggers the translocation of Akt and PDKI to the plasma membrane, where they interact with PIP3 through their $\mathrm{PH}$ domain. Subsequently,Akt is phosphorylated by PDKI in its Thr308 residue and by other kinases such as mTOR in its Ser473 residue. C) Negative regulation of Akt activation. The phosphatases PTEN and SHIP (in grey) promote the blockade of Akt translocation to the plasma membrane by dephosphorylation of PIP3 (in red) in PIP2 (in green). Additionally, CTMP (in blue) negatively regulates Akt activation preventing its phosphorylation in Ser473 and Thr308. 


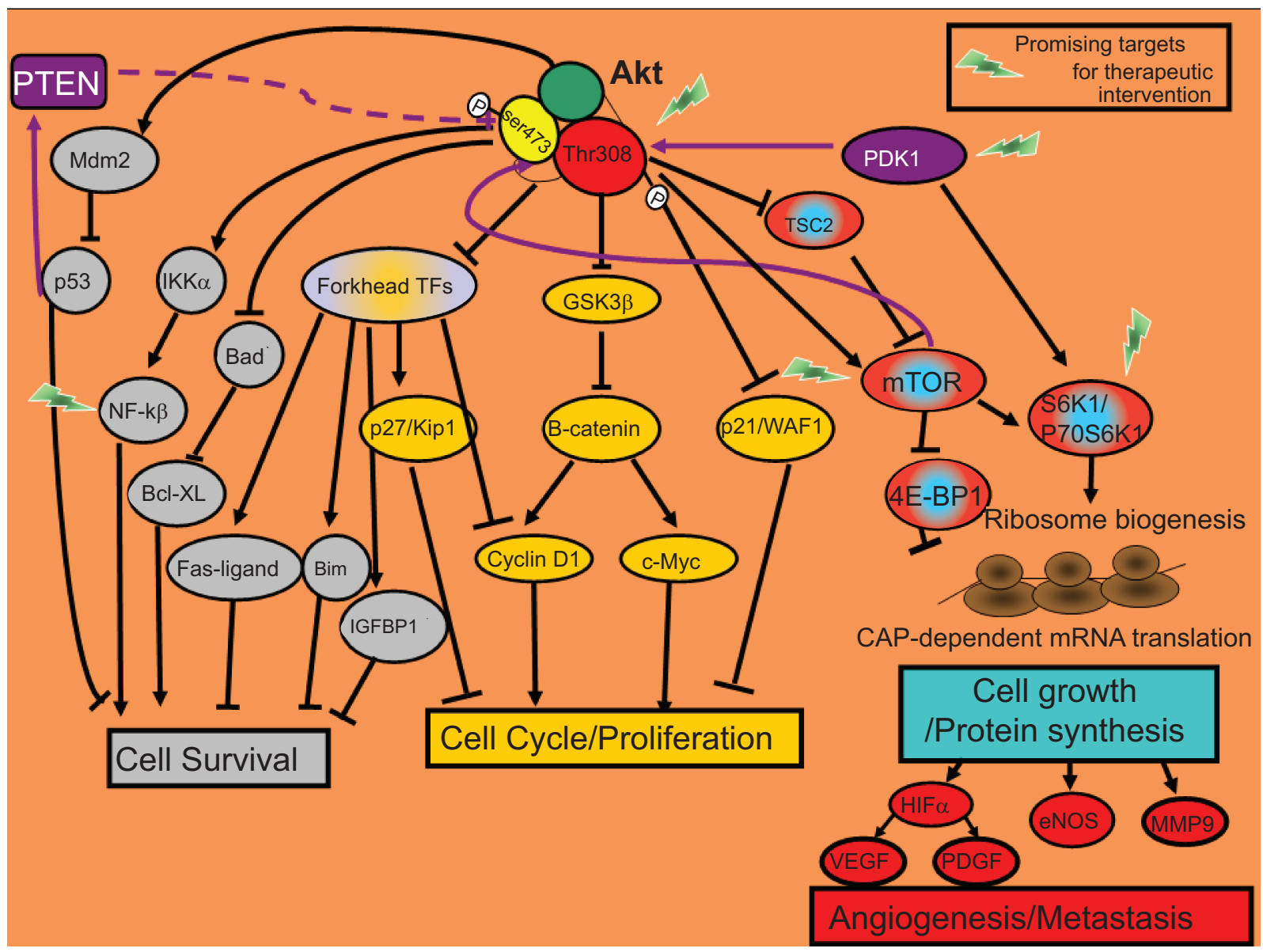

Figure 2 Biological functions of Akt signaling. Most of the cellular responses controlled by Akt are related to cancer. Once active, Akt regulates the activity of other intracellular signaling proteins that will trigger changes in the expression of specific genes that encode for proteins involved in cell survival (in grey) or proliferation/cell cycle (in yellow). Additionally, by activation of the mTOR protein, Akt will enhance the translation of specific mRNAs. TOP-dependent mRNAs that encode for proteins involved in ribosome biogenesis and also the translation of CAP-dependent mRNAs that encode for proteins with key cellular functions such as angiogenesis and metastasis (in red-blue).

The transcription factor, HIF, which controls the expression of hypoxia-inducible genes, is a heterodimer of two subunits (HIF- $\alpha$ and HIF- $\beta$ ). In each cell, HIF- $\beta$ is constitutively expressed, whereas the intracellular amount of HIF- $\alpha$ is highly controlled at two levels: PI3k/Akt signaling through mTOR at the translational level and pVHL at the post-translational level. ${ }^{36,37}$

pVHL is a component of a ubiquitin ligase complex that promotes the destruction of specific cellular proteins through proteosome degradation. In normal tissue, under normoxic conditions, pVHL recognizes and binds hydroxylated HIF- $\alpha$, which, once bound by $\mathrm{pVHL}$, will be ubiquitinated to be degraded by the proteosome. However, under hypoxic conditions, HIF- $\alpha$, is not hydroxylated, pVHL is not able to recognize HIF- $\alpha$ and, consequently, is not degraded. Stabilized HIF- $\alpha$ is translocated to the nucleus, binds with HIF- $\beta$, and forms a heterodimer that promotes expression of hypoxia-response target genes. ${ }^{37}$
pVHL is lost or inactivated in most clear-cell RCC, and HIF- $\alpha$, although hydroxylated, is not degraded. Accumulated HIF- $\alpha$, leads to increased expression of hypoxia-response genes. ${ }^{37,38} \mathrm{HIF}$-inducible genes are associated with tumorogenesis because they are involved mainly in angiogenesis (VEGF, PDGF, others), proliferation and survival (transforming growth factor alpha [TGF- $\alpha$ ], insulin-like growth factor 2 [IGF2], and others), metabolism, and $\mathrm{pH}$ regulation. . $^{37,38}$

The characterization of PI3K-Akt-mTOR in metastatic RCC patients using the UCLA RCC tissue array showed that loss of PTEN increased in all RCC patients with a greater loss in clear-cell tumors and sarcomatoid tumors. The presence of active Akt (pAkt) was greatest in collecting duct carcinoma followed by clear-cell carcinoma and loss of PTEN correlated with pAkt $(\mathrm{p}=0.028)$ and HIF- $\alpha$ expression $(\mathrm{p}<0.0001)$. Active p70 S6K (pS6K) was also highly expressed by sarcomatoid and clear-cell tumors (higher expression in high-grade and in high-stage).$^{36}$ The mTOR inhibitor temsirolimus has 
recently shown efficacy in non-clear-cell RCC histologic subtypes. ${ }^{39}$ One proposed resistance mechanism for mTOR inhibition is the compensatory upregulation of Akt through the activation of the IGF receptor (IGF-1R) pathway as we will explain in the last section of this review. Accordingly, preclinical data showed by Holland and colleagues established a rationale for the combination of therapies that target Akt and mTOR in RCC patients. ${ }^{40}$

Additionally, immunohistochemical analyses have also revealed that no patient who had low expression of $\mathrm{pS} 6 \mathrm{~K}$ or pAkt was a responder to this mTOR inhibitor. ${ }^{41}$ Pre-clinical assays with RCC cell lines have also shown that a loss of pVHL sensitized cells to temsirolimus, both in vitro and in mouse xenograft models, suggesting that loss of pVHL could be a predictive marker of the response to mTOR blockade. ${ }^{42}$ Furthermore, PTEN-deficient tumor cell lines with high levels of pAkt were also more sensitive to the effects of temsirolimus in vitro. ${ }^{43}$ In this molecular scenario, the Akt pathway is a promising target in the treatment of metastatic RCC. In fact, the mTOR inhibitor temsirolimus has been already approved for the first line treatment of poor risk advanced RCC patients ${ }^{44}$ and clinical trials with the mTOR inhibitor everolimus are currently underway to show its efficacy in RCC patients. ${ }^{45}$

\section{Breast cancer}

Hormone receptor- and HER2-positive breast cancer currently account for $75 \%-80 \%$ and $15 \%-20 \%$ of breast cancer cases, respectively, with about half of HER2-positive cases co-expressing hormone receptors. The remaining $10 \%-15 \%$ of breast cancer cases do not express HER2 and hormone receptors and are called triple-negative breast cancers. ${ }^{46}$ Evidence shows PI3K pathway aberrations in breast tumors and suggests that this pathway may play a distinct role in the pathogenesis of different breast cancer molecular subtypes.

The analysis of 64 hormone receptor-positive-Her2negative breast cancer samples from patients with stage I to III tumors managed with hormonotherapy \pm chemotherapy showed that the activation of the PI3K/Akt pathway was higher in those tumors with less hormone receptor levels and was also associated with adverse outcome. ${ }^{47}$

Recently, a genomic analysis of PIK3CA, PTEN, and $A k t$ mutations in a collection of 547 breast cancer samples showed that PIK3CA mutations were more common in hormone receptor-positive (34.5\%) and HER2-positive (22.7\%) than in triple-negative tumors (8.3\%). Akt1 (1.4\%) and PTEN (2.3\%) mutations were restricted to hormone receptor-positive cancers. However, PIK3CA mutations did not have a significant effect on outcome after adjuvant tamoxifen therapy in a population of 157 hormone receptor-positive breast cancer patients. ${ }^{48}$

HER2 overexpression in breast cancer is associated with a high recurrence rate, poor survival, and resistance to chemotherapy and endocrine therapy. ${ }^{49,50} \mathrm{PI} 3 \mathrm{~K} / \mathrm{Akt}$ and Ras/MAPK pathways are the major mediators of HER2 signaling. ${ }^{51}$ Accordingly, tumor cells in which HER2 is overexpressed exhibit constitutive Akt activity. ${ }^{52}$ Furthermore, immunohistochemical analysis of breast cancer samples indicated a possible role of PI3K/Akt/mTOR signaling in HER2-mediated breast cancer progression and has suggested its association with poor disease-free survival. Additionally, it has been suggested that the anti-HER2 agent trastuzumab depends on the intact PTEN for its action in HER2 overexpressing breast cancer cell lines and that the loss of PTEN predicts for trastuzumab resistance. ${ }^{33}$ Therefore, Akt blockade could represent a promising strategy to treat breast cancer patients who are trastuzumab resistant. ${ }^{53,54}$ Moreover, an oral dual tyrosine kinase inhibitor (TKi) of epidermal growth factor receptor (EGFR) and HER2, as a single agent, promotes, apoptosis in trastuzumab-resistant breast cancer cell lines. In these cells, its cytotoxic effect is correlated with the blockade of the activation of Akt, p70 S6K, and MAPK. ${ }^{53}$ Furthermore, lapatinib also sensitizes HER2-positive breast cancer cells to other therapies such as radiation and also restores tamoxifen sensitivity in tamoxifen-resistant breast cancer models suggesting that this ability of lapatinib may be due to the inhibition of the PI3K-Akt signaling pathway. Accordingly, pre-clinical models also show that failure to inhibit Akt activation leads to resistance to therapies with TKIs against HER-family. ${ }^{26,55-58}$

Akt activity also promotes resistance to chemotherapy in breast cancer cell lines, ${ }^{54}$ and recent findings correlate pAkt levels and HER2 status with resistance to endocrine therapy in metastatic breast cancer. ${ }^{59}$ A retrospective study with tumor samples from 36 metastatic breast cancer patients treated with endocrine therapy showed 12 cases $(33.4 \%)$ with pAkt. In the pAkt-positive patients, endocrine therapy proved less efficacious than in pAkt-negative patients $(\mathrm{p}<0.01)^{54}$ and pAkt was associated with a poor objective response $(\mathrm{p}<0.05)$. Clinical benefit was also lower in HER2-positive patients $(\mathrm{P}<0.05)$ and was the lowest in the HER2 and pAkt-positive patients $(\mathrm{p}<0.01)$. Therefore, evidence suggests that $\mathrm{pAkt}$ may be a useful predictor of resistance to chemotherapy and endocrine therapy for breast cancer. These data suggest that inhibition of Akt activation in breast cancer patients may increase the efficacy of endocrine therapy and chemotherapy.

Based on the above evidence, clinical trials that explore the efficacy of the mTOR inhibitors temsirolimus and everolimus 


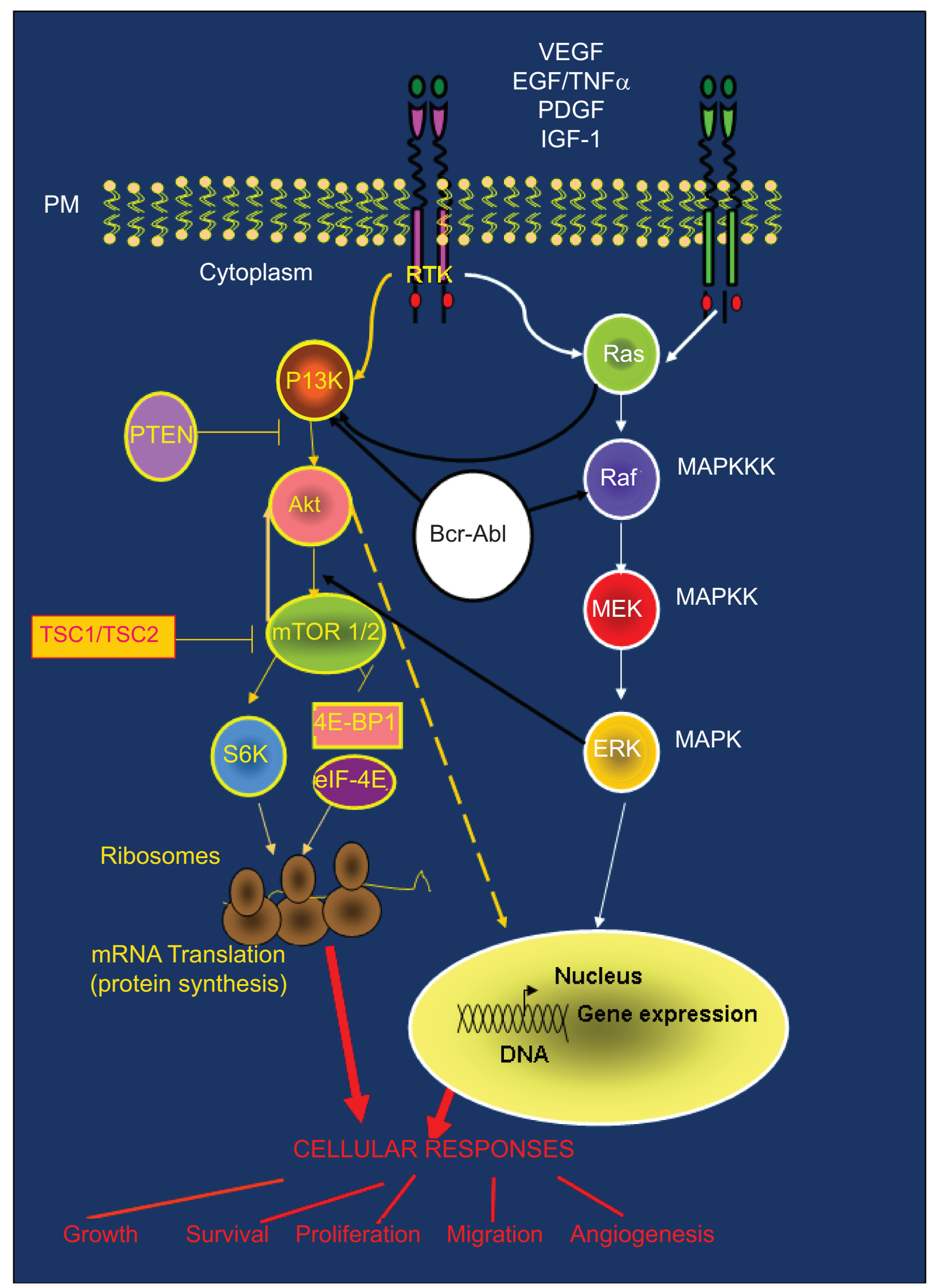

Figure 3 PI3K-Akt-mTOR pathway and cross-talk with other signaling cascades: (Ras/Raf/MAPK AND BCR-ABL). PI3K-Akt and Ras/Raf/MAPK pathways are common routes that control key cellular responses. The large amount of cross-talk between these pathways is often responsible for treatment resistance. 
alone or in combination with aromatase inhibitors in hormone receptor positive breast cancer patients are underway. ${ }^{60-62}$

Regarding triple-negative breast cancer, one of its molecular features is the overexpression of genes that encode for the TKRs EGFR and c-KIT that lead to abundant MAPK and Akt signaling activation downstream. Therefore, Akt could be also a promising target for the treatment of triplenegative breast cancer. ${ }^{46}$

In conclusion, these findings suggest that Akt activation should be used as a molecular marker in breast cancer patients to predict treatment response. The blockade of Akt activation in combination with current therapies may be also considered a novel therapeutic approach in most breast cancer molecular subtypes.

\section{Non-small cell lung cancer}

Pre-clinical data have shown that pAkt is also active in most NSCLC cell lines and that the modulation of Akt activity (by pharmacological or genetic approaches) sensitizes cells to chemotherapy and radiation. ${ }^{58} \mathrm{~A}$ correlation between pAkt and poor prognosis has been also established for all stages of NSCLC. ${ }^{63,64}$ Tang and colleagues reported that loss of PTEN and the presence of pAkt is correlated with poor differentiation, lymph node involvement, distant metastasis, and late stages in NSCLC patients. ${ }^{65}$ Therefore, the combinations of drugs that modulate Akt activation with the therapeutic modalities typically used in NSCLC are thought to improve treatment response.

Additionally, while some authors have reported the possible role of pAkt as a predictive marker of response to gefitinib, an oral small molecule that blocks EGFR, in NSCLC patients with specific EGFR mutations, others have failed to find any association. Sordella and colleagues showed that these EGFR mutants selectively activate the Akt survival pathway. ${ }^{66}$ Cappuzo and colleagues reported that gefitinib was more effective in patients with pAkt-positive tumors. These patients showed better response rates, disease control rates, and times to progression than patients with pAkt-negative tumors. ${ }^{67}$ Other authors have indicated that although no significant correlation between EGFR mutations and expression of pAkt was detected in gefitinib-treated patients, pAkt overexpression was associated with prolonged time to progression. ${ }^{68}$ Consistent with these findings, pre-clinical studies have shown that those EGFR mutations that sensitize to gefitinib selectively activated the Akt pathway. High sensitivity to EGFR TKIs in NSCLC seemed to be closely correlated with dependence on Akt activation in response to EGFR signaling. ${ }^{65,69}$ Therefore, further studies are necessary to confirm whether the assessment of pAkt status could be a useful complementary test for the identification of EGFR-positive NSCLC patients with the highest possibility of profiting from TKIs.

Exposure to cigarette smoke (active or passive) is the main cause of lung cancer. ${ }^{70}$ The presence of nicotinic acetylcholine receptors in NSCLC cell lines and primary tissues has been documented. ${ }^{71,72}$ After exposure to nicotine, Akt is phosphorylated in NSCLC cells. The Akt activation induced by nicotine leads to an increase in its downstream effectors and confers resistance to NSCLC cells treated with chemotherapeutic agents. $^{69,71}$ Furthermore, it has been shown that nicotine in NSCLC cells promotes resistance to TKIs such as gefitinib. ${ }^{69}$

\section{Pancreatic cancer}

High levels of pAkt have been detected in $40 \%-70 \%$ of pancreatic cancers and $60 \%$ of tumors show EGFR amplification. Therefore, these proteins and their downstream effectors could be new therapeutic targets for treatment, as well as useful molecules for diagnosis and prognosis. ${ }^{73}$ In fact, erlotinib, an oral small-molecule anti-EGFR, has been approved by the US Food and Drug Administration (FDA) for the treatment of locally advanced or metastatic pancreatic cancer. EGF receptor-related protein (ERRP), a novel EGFR-negative modulator has also shown anti-tumor activity in pre-clinical studies through its ability to downregulate molecular markers such as Akt, NF- $\mathrm{KB}$, and MAPK. ${ }^{74,75}$ Buck and colleagues also showed that the combination of the mTOR inhibitor rapamycin with erlotinib has anti-tumor activity in human pancreatic cancer cell lines that do not respond to erlotinib in monotherapy. These authors suggest that although erlotinib could not downregulate baseline Akt activity in pancreatic cancer-resistant cell lines, it could synergize with rapamycin by inhibiting the stimulated Akt activity induced by rapamycin. ${ }^{76}$ Indeed, strategies aimed at blocking Akt activation could be promising for the treatment of pancreatic cancer.

\section{Hormone-refractory prostate cancer}

Metastatic hormone-refractory prostate cancer (HRPC) patients show enhanced Akt activity. Some also show loss of PTEN, which leads to the activation of downstream Akt anti-apoptotic effectors such as Bcl-xl, Bcl-2 (B-cell lymphoma 2), and NF- $\kappa B$, and other Akt effectors such as $\mathrm{mTOR} / \mathrm{p} 70 \mathrm{~S} 6 \mathrm{~K} .{ }^{77,78}$

The current reference treatment for HRPC consists mainly of chemotherapy with docetaxel. However, interference with cell survival, through pro-apoptotic drugs, combined with docetaxel is a new approach. ${ }^{78}$ Clinical trials with agents that reduce the expression of anti-apoptotic $\mathrm{Bcl}-2$ proteins 
are ongoing (a phase II study with oblimersen sodium plus docetaxel), studies with anti-NF- $\mathrm{B}$ therapies have been reported (phase I/II studies with thalidomide, arsenic trioxide, and bortezomib), and also the mTOR inhibitors (rapamycin, temsirolimus, and everolimus) have also produced good results in pre-clinical models. Nevertheless, a phase II clinical study with the Akt inhibitor perifosine showed poor results. ${ }^{76,78}$

\section{Gastric cancer}

In the last American Society of Clinical Oncology (ASCO) annual meeting, $\mathrm{Xu}$ and colleagues showed that 148 (78.7\%) were positive for $\mathrm{p}$-Akt among 188 gastric adenocarcinoma samples. High expressions of $\mathrm{p}$-Akt were significantly correlated with pTNM stage $(\mathrm{p}=0.031)$, depth of invasion $(\mathrm{p}<0.001)$, lymph node metastasis $(\mathrm{p}<0.001)$ and differentiated levels $(\mathrm{p}<0.012){ }^{79}$

Additionally, Oki and colleagues have shown a direct correlation between Akt activation and chemoresistance in gastric cancer. Analysis of primary gastric carcinoma tissue and corresponding normal mucosa from gastric cancer patients who underwent surgery showed that Akt activation and loss of PTEN were associated with increased resistance to several chemotherapeutic agents. ${ }^{80,81}$ A pre-clinical study also showed that those chemotherapeutic agents that induced apoptosis in human gastric cancer cell lines downregulated the PI3K-Akt pathway. ${ }^{80}$

Additionally, pAkt levels were associated with the efficacy of some adjuvant chemotherapy regimens and indicated the association between pAkt levels with poor prognosis for T3/T4 gastric cancer patients. ${ }^{82}$

Although further studies are necessary to establish the predictive value of Akt signaling in sensitivity/resistance to gastric cancer therapies, these data suggest that drug combinations including Akt inhibitors may improve response in patients with gastric cancer.

\section{Hepatocellular carcinoma}

Alterations in the TKR c-Met have been involved in HCC (hepatocellular carcinoma) progression. ${ }^{83}$ In human HCC cell lines, hepatocyte growth factor (HGF) uses its association with c-Met to promote the activation of the PI3K-Akt pro-survival pathway, which led to suppression of the proapoptotic signals mediated by Fas. ${ }^{84}$ Fas is a membrane receptor that induces apoptosis after binding its ligand FasL onto the surface of T-cells. Fas/FasL signaling seems to mediate chemosensitivity in pre-clinical models of HCC. ${ }^{85}$ Those HCC cell lines that respond to chemotherapy show increased Fas/FasL-mediated apoptosis. c-Met, through its ability to activate Akt, may be involved in resistance to those chemotherapeutic agents that mediate its cytotoxic effect by stimulating the Fas-FasL apoptotic pathway.

EGFR, IGF2, and its receptor IGF-1R are also detected in HCC cell lines and cross-talks between EGFR and IGF-1R have been reported in different tumor types. IGF2-IGF-1R activates proliferation through Ras/MAPK pathway and survival by means of PI3K/Akt. ${ }^{86,87}$ In fact, gefitinib alone was not able to completely prevent the development of HCC in pre-clinical models ${ }^{86}$ and IGF2-IGF-1R may contribute to gefitinib resistance in $\mathrm{HCC}$ cells through the activation of PI3K/Akt pathway. Treatment of HCC cell lines with gefitinib blocked Akt activation induced by EGFR itself, although gefitinib had no effects on the Akt activation induced by IGF2-IGF1R; therefore, it could not cause the death of the tumor cells by itself.

Additionally, a selective IGF-1R inhibitor was able to induce apoptosis in these $\mathrm{HCC}$ cells and its cytotoxic effect was boosted by gefitinib. ${ }^{88}$ Therefore, the IGF2/IGF-1R survival signal promoted by the activation of Akt may contribute to gefitinib resistance in HCC. In this setting, the pharmacological combination of gefitinib with anti-IGF-1R antibody or inhibition downstream in the pI3K-Akt pathway could enhance the anti-tumor effects reached by gefinitib as a single agent in HCC.

\section{Brain tumors}

The PI3K-Akt pathway is relevant in glioma initiation and progression. ${ }^{89}$ PTEN is frequently lost or mutated in highgrade gliomas and most of these tumors have elevated Akt activity. Gliomas also seem to be good targets for therapies based on inhibitory compounds of the PI3K-Akt-p70 S6K pathway.

Recently, activation of the Akt pathway in 101 neuroblastoma samples was also tested: $60 \%$ of the tumor samples expressed PI3K, 80\% Akt, and 73\% pAkt. In addition, p70 S6K was expressed in $95 \%$ of tumors. Akt and pAkt also showed higher expression in metastases than in primary tumors. ${ }^{90}$

\section{Akt inhibitors}

As we described above, PI3K-Akt-mTOR pathway plays a critical role in proliferation and survival in tumor cells and is also linked with resistance to radiotherapy, chemotherapy, endocrine therapy and novel anticancer therapies. ${ }^{91-94}$ In this setting, this pathway seems to bring together all the characteristics of a good target for the treatment of cancer. Currently, clinical trials with inhibitors of the PI3K-Akt pathway in monotherapy or in combination with other anti- 
cancer drugs are underway in cancer patients. In addition, these novel inhibitors are being also tested in chemo- and hormonal therapy refractory patients..$^{95,96}$

Although in this review we will focus on inhibitors of Akt, currently PI3K and mTOR inhibitors are more advanced in their development than Akt inhibitors. In fact, a new generation of PI3K inhibitors is emerging. Some of them, such as NVP-BEZ235, a synthetic low molecular weight compound belonging to the class of imidazoquinolins, which potently and reversively inhibits class I PI3K catalytic activity by competing with the ATP is in early phase clinical trials. ${ }^{97}$ And as we mentioned above, the rapamycin-derivated temsirolimus and everolimus, as mTOR inhibitors, have been already approved for the treatment of same cancer patients and clinical trials to explore their efficacy in new tumor types are currently underway. ${ }^{16,41,98}$ Furthermore, rapamycin analogs lead to an increase in PI3K and Akt activation, through a feedback mechanism mediated by IGF-1R. Therefore, this Akt activation may counteract the inhibition of mTOR. Combined treatment with mTOR inhibitors and anti-IGF-1R monoclonal antibodies (MAbs) are currently being tested in caner patients. ${ }^{99}$ In addition, due to the cross-talk between ER and PI3K/Akt/mTOR pathways, clinical trials with mTOR inhibitors and endocrine therapy are also underway. ${ }^{60}$

In this context, the use of anti-target agents that block selectively each Akt isoforms or the use of dual inhibitors that block this pathway in two levels (pg, dual Akt-S6K small inhibitors, dual mTOR complex 1 and 2 inhibitors, etc) may improve the results reached with the current mTOR inhibitors. During recent years, intense efforts made in the search for Akt inhibitors have yielded several promising candidates, such as lipid-based inhibitors that compete with PIP3 to bind the PH domain of Akt, ATP-competitive inhibitors, smallmolecule inhibitors, and peptide-based inhibitors reviewed elsewhere. ${ }^{100,101}$

The lipid-based inhibitors include perifosine (KRX-0401), an orally active membrane-permeable ether lipid with a single long alkyl chain that inhibits the translocation of all Akt isoforms to the membrane. In vitro, perifosine has antiproliferative effects in many tumor cell lines and sensitizes tumor cells to radiation and chemotherapy. Perifosine has also shown efficacy and tolerability in phase I clinical trials. ${ }^{102}$ However, the lack of objective responses as a single agent has been observed in several recent phase II trials in patients with malignant melanoma, prostate cancer, head and neck cancer, and pancreatic adenocarcinoma. ${ }^{101}$ Phase II trials with perifosine combined with radiotherapy, chemotherapy or other anticancer agents, such as imatinib mesylate and trastuzumab, are ongoing. ${ }^{100}$ In the last ASCO annual meeting, preliminary results from a phase I study from a multicenter trial of perifosine plus in patients with advanced solid tumors were reported. Accrual is in the last cohort. To

Table I Akt signaling deregulation in tumors. Association with resistance to treatment

\begin{tabular}{|c|c|}
\hline Alteration & Tumor \\
\hline $\begin{array}{l}\text { Increase in Akt protein/activity, } 23 \%-50 \%{ }^{114} \\
\text { PTEN mutation/loss, } 37 \%{ }^{115} \\
\text { PI3K alteration, } 4 \%{ }^{116}\end{array}$ & Lung \\
\hline $\begin{array}{l}\text { Increase in Akt protein/activity, } 38 \%{ }^{117} \\
\text { PTEN mutation/loss, } 31 \%{ }^{118} \\
\text { TSCI/TSC2 alteration }{ }^{119}\end{array}$ & Kidney \\
\hline $\begin{array}{l}\text { Increase in Aktl protein/activity, } 24 \%-40 \%{ }^{120} \\
\text { Increase in Akt2 protein/activity }>90 \% \text { ErbB-2hi }{ }^{121} \\
\text { PTEN mutation/loss, } 15 \%-41 \%{ }^{122} \\
\text { PI3K alteration, } 24-42 \%{ }^{123}\end{array}$ & Breast \\
\hline TSCI/TSC2 alteration ${ }^{124}$ & Neuroendocrine tumors \\
\hline $\begin{array}{l}\text { Increase in Akt I protein/activity, } 34 \%-50 \% 125 \\
\text { PTEN mutation/loss, } 30 \%-63 \%{ }^{126}\end{array}$ & Prostate \\
\hline $\begin{array}{l}\text { Increase in Akt2 expression, } 46 \%^{127} \\
\text { PTEN mutation/loss, } 35 \%^{128} \\
\text { PI3K alteration, } 20 \%-32 \%^{128,129}\end{array}$ & Colon \\
\hline High Akt activity ${ }^{130}$ & Pancreas \\
\hline $\begin{array}{l}\text { High Akt activity }{ }^{131} \\
\text { Loss of PTEN }{ }^{132,133}\end{array}$ & Gastric Cancer \\
\hline $\begin{array}{l}\text { High Akt activity } \\
\text { PTEN mutation/loss }\end{array}$ & Brain Tumors \\
\hline
\end{tabular}


date no unexpected toxicities and clinical activity has been noted within the first three cohorts with four of six $(67 \%)$ evaluable patients with advanced cancer achieving at least stable disease for more than six months. One partial response has been also seen. ${ }^{103}$

Triciribine phosphate monohydrate (TCN-P; VQD-002, VioQuest Pharmaceuticals, Basking Ridge, NJ, USA) is an old anticancer agent discovered more than 35 years ago that was discontinued due to severe side effects at high doses. The discovery of triciribine as a potent and selective inhibitor of Akt has led to renewed interest in its further development. VQD-002 works as a pan-Akt inhibitor that targets the $\mathrm{PH}$ domain of Akt. It inhibits the growth of human tumors that overexpress Akt in mice at low doses without visible side effects. VQD-002 has demonstrated compelling preclinical activity in combination with other targeted therapies (trastuzumab and TKIs) in many tumor types, such as glioblastoma, lymphomas, refractory leukemia, breast, colon, NSCLC, and prostate. ${ }^{104}$ VQD-002 is in Phase I/IIa clinical trials in solid and hematological tumors. ${ }^{101}$

GSK690693 is an Akt ATP-pocket binder developed by GSK with $\mathrm{IC}_{50}$ values of $2 \mathrm{nM}, 13 \mathrm{nM}$, and $9 \mathrm{nM}$ against Akt1, Akt2, and Akt3, respectively. ${ }^{101}$ In vitro, GSK690693 showed a strong additive effect in a variety of tumor cells when combined with other anti-target drugs such as lapatinib. It also showed significant efficacy in xenograft models from ovarian (SK-OV-3), prostate (LNCaP), and breast (BR474, HCC-1954) carcinoma cell lines. Phase I clinical trials in patients with solid tumors and lymphomas treated with intravenous GSK690693 are underway. ${ }^{105,106}$

XL418 is an orally active and low-nanomolar dual Akt and p70 S6K inhibitor developed by Exelisis Inc. (San Francisco, CA, USA) that also acts as an ATP-pocket binder. ${ }^{101}$ It has already demonstrated good in vivo efficacy in several xenograft models, including lung (A549) and breast adenocarcinoma (MCF7) tumor cell lines as a single agent or in combination with chemotherapeutic drugs such as paclitaxel. It has also been shown to enhance apoptosis in combination with TKIs that target EGFR, HER2, and VEGFR. A phase I clinical trial with this drug is ongoing.

Therefore, we can see that perifosine and VQD-002 block Akt activation through their interaction with the $\mathrm{PH}$ domain of Akt, ${ }^{101}$ whereas GSK690693 and XL418 inhibit the kinase activity of the active Akt through binding to its ATP pocket.

Treatment with pan-Akt inhibitors has shown unexpected toxicity. One of these side effects includes hyperglycemia. GSK690693 leads to increased blood glucose and insulin levels, although these return to baseline levels as the circulating drug concentration decreases. This side effect was also observed in clinical trials with perifosine and triciribine phosphate. ${ }^{101}$ The hyperglycemia induced by these inhibitors is consistent with the phenotype of the Akt2 knockout mice. ${ }^{107}$ Another pan-Akt inhibitor developed by Abbott, a series of 3,5-disubstituted pyridines (A-443654 and A-6745639), was reported to cause severe hypotension in rats and dogs that could be partly due to inhibition of other kinases. ${ }^{100}$

Regarding the feedback mechanism mediated by IGF1-R, the inhibition of Akt or mTOR complex 1 leads to subsequent suppression of phosphorylation of p70 S6K, which inhibits the phosphorylation and subsequent inactivation of insulin receptor substrate 1 (IRS-1) by p70 S6K. Activation of IRS-1 promotes the insulin-stimulated activation of Akt via PI3K. ${ }^{12,101,108-110}$ Therefore, this Akt activation might attenuate the therapeutic effects reached with the mTOR complex 1 inhibitors, although the combination rapamycin analogs with therapies that simultaneously prevent subsequent Akt activation (pg, MAbs against IGF1-R, and others) might be more effective. In this sense, significant synergy between mTOR inhibitors and anti-TKR drugs has also been observed. ${ }^{101}$ In fact, dual inhibition with the mTOR inhibitor everolimus combined with a monoclonal antibody against IGF-1R results in a supra-additive growth inhibitory effect both in vitro and in vivo in breast cancer models. ${ }^{13}$ Clinical studies with this combination in breast cancer patients are planned.

The search for small molecule inhibitors that interact with the allosteric site of Akt represents a new frontier in drug discovery. In this regard, Merck and Co, Inc. (Whitehouse Station, NJ, USA) has synthesized allosteric isoform-selective Akt inhibitors that are able to inhibit Akt kinase activity (like the ATP pocked binders) and in addition the activation of Akt by phosphorylation. ${ }^{101}$ In this setting, the activation of Akt via the feedback mechanism would be abolished. Therefore, these allosteric Akt inhibitors should be more efficient than the ATP-pocket binders in attenuating Akt activity. However, preliminary studies have revealed that the effect of single isoform inhibition is not superior to the simultaneous inhibition of Akt1 and Akt2 with pan-Akt inhibitors. ${ }^{101}$

Another trend in this area is the search for novel Akt inhibitors that bind to other sites of Akt, based on the fact that activity and function of Akt are also regulated by many interacting proteins. ${ }^{101}$ Akt-in is a peptide composed of 15 amino acids designed to mimic the interaction between Akt and a physiological coactivator, T-cell leukemia/ lymphoma 1 (TCL1). The Akt-in sequence encompasses a portion of the TCL1 protein that binds Akt in its $\mathrm{PH}$ domain 
and inhibits Akt kinase activity and membrane translocation in cell lines. It also inhibits tumor cell proliferation in preclinical models but has poor oral bioavailability and cellular penetration. Other approaches use the consensus protein sequence preferred by Akt to develop pseudopeptide substrates that have been shown to inhibit Akt and the growth of cancer cells in vitro. ${ }^{111,112}$

Akt antisense inhibitors that block Akt translation are also being developed. RX-0201 is a 20-mer oligonucleotide with a sequence complementary to that of Akt-1 mRNA that inhibits the expression of Akt-1 in tumor cell lines and bears significant in vitro and in vivo anticancer activity with good safety. A phase I trial with RX-0201 that aimed to determine the maximum tolerated dose and pharmacokinetic and safety profile of RX-0201 was reported at the last ASCO meeting and phase II clinical trials are being planned. ${ }^{113}$

\section{Summary}

A more in-depth knowledge of the molecular pathogenesis of cancer has led to the discovery of new tumor targets. These are aimed at targets located on the cell membrane and inside the cell. The newly approved target-based anticancer agents (erlotinib, gefitinib, lapatinib, trastuzumab, cetuximab, sunitinib, sorafenib, imatinib, dasatinib, and temsirolimus) have not only shown efficacy in terms of response rate and progression-free survival, but also a good safety profile.

The PI3K/Akt pathway emerges as one of the most promising targets in the immediate future. Pharmaceutical companies are developing new agents against this pathway. Hopefully, these new agents will become part of the antitumor armamentarium.

\section{Abbreviations}

4EBP-1, 4E-binding protein 1; AGC, protein kinase A/protein kinase $\mathrm{G} /$ protein kinase C-like; Bcl-2, B-cell lymphoma 2; CAP, catabolite activator protein; CTMP, carboxyl-terminal modulating protein; DNA-PK, DNA-dependent protein kinase; EGFR, epidermal growth factor receptor; ERRP, EGF receptorrelated protein; GSK3, glycogen synthase kinase-3; HCC, Hepatocellular carcinoma; HER2, human epidermal growth factor receptor-2; HGF, hepatocyte growth factor; HIF-a, hypoxia-inducible factor a; HRPC, hormone-refractory prostate cancer; IGBP-1, immunoglobulin binding protein-1; IGF-1R, insulin-like growth factor receptor 1; IGF2, insulin growth factor-2; IKK, I kappa B kinase complex; IRS-1, insulin receptor substrate 1; Mdm2, murine double minute-2; MMP9, matrix metalloproteinase 9; mTOR, mammalian target of rapamycin; $\mathrm{NF}-\mathrm{kB}$, nuclear factor $\mathrm{\kappa B}$; NSCLC, non-small cell lung cancer; p70 S6K1, S6 kinase-1; PDGF, platelet-derived growth factor; $\mathrm{PH}$, pleckstrin homology; PI3K, phosphatidylinositol 3-kinase; PIP2, inositol 4, 5 biphosphate; PIP3, phosphatidylinositol-3, 4, 5-trisphosphate; PKB protein kinase B; PTEN, phosphatase and tensin homologue; pVHL, von Hippel-Lindau protein complex; RCC, renal cell carcinoma; SHIP, SH2 containing inositol phosphatise; TCL1, T-cell leukemia/lymphoma 1; TGF-a, transforming growth factor alpha; TKI, tyrosine kinase inhibitor; TKRs, tyrosine kinase receptor; TSC1/TSC2, tuberous sclerosis complex; VEGF, vascular endothelial growth factor.

\section{Acknowledgments}

We thank Fátima Cruz, Luisa Martín and Nieves Ruíz-Ayllón for editorial assistance. The authors report no conflicts of interest in this work.

\section{References}

1. Vivanco I, Sawyers CL. The phosphatidylinositol 3-kinase Akt pathway in human cancer. Nat Rev Cancer. 2002;2:489-501.

2. Sarbassov DD, Guertin DA, Ali SM, Sabatini DM. Phosphorylation and regulation of Akt/PKB by the rictor-mTOR complex. Science. 2005;307:1098-1101.

3. Osaki M, Oshimura M, Ito H. PI3K-Akt pathway: its functions and alterations in human cancer. Apoptosis. 2004;9:667-676.

4. Manning BD, Cantley LC. Akt/PKB signaling: navigating downstream. Cell. 2007;129:1261-1274.

5. Luo J, Manning BD, Cantley LC. Targeting the PI3K-Akt pathway in human cancer: rationale and promise. Cancer Cell. 2003;4:257-262.

6. Li Y, Dowbenko D, Lasky LA. Akt/PKB phosphorylation of p21Cip/ WAF1 enhances protein stability of p21Cip/WAF1 and promotes cell survival. J Biol Chem. 2002;277:11352-11361.

7. Wullschleger $\mathrm{S}$, Loewith R, Hall MN. TOR signaling in growth and metabolism. Cell. 2006;124:471-484.

8. Mamane Y, Petroulakis E, LeBacquer O, Sonenberg N. mTOR, translation initiation and cancer. Oncogene. 2006;25(48):6416-6422.

9. Martin DE, Hall MN. The expanding TOR signaling network. Curr Opin Cell Biol. 2005;17(2):158-166.

10. Jacinto E, Loewith R, Schmidt A, et al. Mammalian TOR complex 2 controls the actin cytoskeleton and is rapamycin insensitive. Nat Cell Biol. 2004;6(11):1122-1128.

11. Wan X, Harkavy B, Shen N, Grohar P, Helman LJ. Rapamycin induces feedback activation of Akt signaling through an IGF-1R-dependent mechanism. Oncogene. 2007;26:1932-1940.

12. O'Reilly KE, Rojo F, She QB, et al. mTOR inhibition induces upstream receptor tyrosine kinase signaling and activates Akt. Cancer Res. 2006;66:1500-1508.

13. Di Cosimo S, Scaltriti M, Val D, et al. PI3-K/Akt/mTOR pathway as a target for breast cancer therapy. 2007 ASCO Annual Meeting. Abstract No. 3511.

14. Bjornsti MA, Houghton PJ. The TOR pathway: a target for cancer therapy. Nat Rev Cancer. 2004; (4):335-348.

15. Seeliger H, Guba M, Kleespies A, Jauch KW, Bruns CJ. Role of mTOR in solid tumor systems: a therapeutical target against primary tumor growth, metastases, and angiogenesis. Cancer Metastasis Rev. 2007;26:611-621.

16. Pantuck AJ, Seligson DB, Klatte T, et al. Prognostic relevance of the mTOR pathway in renal cell carcinoma: implications for molecular patient selection for targeted therapy. Cancer. 2007;109(11):2257-2267.

17. Chan TO, Rittenhouse SE, Tsichlis PN. Akt/PKB and other D3 phosphoinositide-regulated kinases: kinase activation by phosphoinositidedependent phosphorylation. Апnи Rev Biochem. 1999;68:965-1014. 
18. Hill MM, Clark SF, Tucker DF, Birnbaum MJ, James DE, Macaulay SL. A role for protein kinase Bbeta/Akt2 in insulin-stimulated GLUT4 translocation in adipocytes. Mol Cell Biol. 1999;19:7771-7781.

19. Summers SA, Whiteman EL, Cho H, Lipfert L, Birnbaum MJ. Differentiation-dependent suppression of platelet-derived growth factor signaling in cultured adipocytes. J Biol Chem. 1999;274:23858-23867.

20. Calera MR, Martinez C, Liu H, Jack AK, Birnbaum MJ, Pilch PF. Insulin increases the association of Akt-2 with Glut4-containing vesicles. $J$ Biol Chem. 1998;273:7201-7204.

21. Kupriyanova TA, Kandror KV. Akt-2 binds to Glut4-containing vesicles and phosphorylates their component proteins in response to insulin. J Biol Chem. 1999;274:1458-1464.

22. Hunter SJ, Garvey WT. Insulin action and insulin resistance: diseases involving defects in insulin receptors, signal transduction, and the glucose transport effector system. Am J Med. 1998;105:331-345.

23. Cho H, Mu J, Kim JK, et al. Insulin resistance and a diabetes mellituslike syndrome in mice lacking the protein kinase Akt2 (PKB beta). Science. 2001;292:1728-1731.

24. Chen WS, Xu PZ, Gottlob K, et al. Growth retardation and increased apoptosis in mice with homozygous disruption of the Akt1 gene. Genes Dev. 2001;2203-2208.

25. Cho H, Thorvaldsen JL, Chu Q, Feng F, Birnbaum MJ. Akt1/PKBalpha is required for normal growth but dispensable for maintenance of glucose homeostasis in mice. J Biol Chem. 2001;276:38349-38352.

26. Sergina NV, Rausch M, Wang D, et al. Escape from HER-family tyrosine kinase inhibitor therapy by the kinase-inactive HER3. Nature. 2007;445:437-441.

27. Bellacosa A, Kumar CC, Di Cristofano A, Testa JR. Activation of Akt kinases in cancer: implications for therapeutic targeting. Adv Cancer Res. 2005;94:29-86.

28. Samuels Y, Diaz LA Jr, Schmidt-Kittler O, et al. Mutant PIK3CA promotes cell growth and invasion of human cancer cells. Cancer Cell. 2005;7(6):561-573.

29. Rodriguez-Viciana P, Warne PH, Dhand R, et al. Phosphatidylinositol3-OH kinase as a direct target of Ras. Nature.1994;370:527-532.

30. Maru Y. Molecular biology of chronic myeloid leukemia. Int J Hematol. 2001;73:308-322.

31. Cicenas J. The potential role of Akt phosphorylation in human cancers. Int J Biol Markers. 2008;23(1):1-9.

32. Engelman JA, Luo J, Cantley LC. The evolution of phosphatidylinositol 3-kinases as regulators of growth and metabolism. Nat Rev Genet. 2006;7:606-619.

33. Nagata Y, Lan KH, Zhou X, et al. PTEN activation contributes to tumor inhibition by trastuzumab, and loss of PTEN predicts trastuzumab resistance in patients. Cancer Cell. 2004;6:117-127.

34. Fukuda R, Hayashi A, Utsunomiya A, et al. Alteration of phosphatidylinositol 3-kinase cascade in the multilobulated nuclear formation of adult T cell leukemia/lymphoma (ATLL). Proc Natl Acad Sci U S A. 2005;102:15213-15218.

35. Knobbe CB, Reifenberger J, Blaschke B, Reifenberger G. Hypermethylation and transcriptional downregulation of the carboxylterminal modulator protein gene in glioblastomas. $J$ Natl Cancer Inst. 2004;96:483-486.

36. Cohen HT, McGovern FJ. Renal-cell carcinoma. $N$ Engl J Med. 2005;353:2477-2490.

37. Haase VH. The VHL/HIF oxygen-sensing pathway and its relevance to kidney disease. Kidney Int. 2006;69:1302-1307.

38. Semenza GL. Targeting HIF-1 for cancer therapy. Nat Rev Cancer. 2003;3:721-732.

39. Hudes G, Carducci M, Tomczak P, et al. A phase III, randomized, 3 -arm study of Temsirolimus (TEMSR) or interferon- $\alpha$ (IFN) or the combination of TEMSR + IFN in the treatment of first-line, poor-risk patients with advanced renal cell carcinoma. ASCO Annual Meeting Proceedings. J Clin Oncol. 2006;24. Abstract LBA4.

40. Holland WS. Preclinical rationale for combination targeted therapy in advanced clear cell renal cell carcinoma (RCC): Abrogation of rapamycin-mediated induction of Akt phosphorylation by perifosine. 2008 ASCO Annual Meeting. Abstract-No.16083
41. Cho D, Signoretti S, Regan M, Mier JW, Atkins MB. The role of mamma lian target of rapamycin inhibitors in the treatment of advanced renal cancer. Clin Cancer Res. 2007;13(2 Pt 2):758s-763s.

42. Thomas GV, Tran C, Mellinghoff IK, et al. Hypoxia-inducible factor determines sensitivity to inhibitors of mTOR in kidney cancer. Nat Med. 2006;12:122-127.

43. Shi Y, Gera J, Hu L, et al. Enhanced sensitivity of multiple myeloma cells containing PTEN mutations to CCI-779. Cancer Res. 2002;62: 5027-5034.

44. Hudes G, Carducci M, Tomczak P, et al; Global ARCC Trial. Temsirolimus, interferon alfa, or both for advanced renal-cell carcinoma. N Engl J Med. 2007;356(22):2271-2281.

45. Motzer J. RAD001 vs placebo in patients with metastatic renal cell carcinoma (RCC) after progression on VEGFr-TKI therapy: Results from a randomized, double-blind, multicenter Phase-III study R. 2008 ASCO Annual Meeting. Abstract No. LBA5026.

46. Cleator S, Heller W, Coombes RC. Triple-negative breast cancer: therapeutic options. Lancet Oncol. 2007;8:235-244.

47. Gonzalez-Angulo AM, Hennessy BT, Meric-Bernstam F, et al. Activation of the PI3K/Akt signal transduction pathway is inversely associated with estrogen receptor levels and correlates with survival in hormone receptor-positive Her2/neu-negative breast cancer. J Clin Oncol. 2007;25:18S. Abstract No. 10588 .

48. Stemke-Hale K, Gonzalez-Angulo AM, Lluch A, et al. An integrative genomic and proteomic analysis of PIK3CA, PTEN, and Akt mutations in breast cancer. Cancer Res. 2008;68(15):6084-6091.

49. Alaoui-Jamali MA, Paterson J, Al Moustafa AE, Yen L. The role of ErbB-2 tyrosine kinase receptor in cellular intrinsic chemoresistance: mechanisms and implications. Biochem Cell Biol. 1997;75:315-325.

50. Kurokawa H, Arteaga CL. Inhibition of erbB receptor (HER) tyrosine kinases as a strategy to abrogate antiestrogen resistance in human breast cancer. Clin Cancer Res. 2001;7(Suppl):4436s-4442s; discussion 4411s-4412s.

51. Olayioye MA, Neve RM, Lane HA, Hynes NE. The ErbB signaling network: receptor heterodimerization in development and cancer. EMBO J. 2000;19:3159-3167.

52. Zhou X, Tan M, Stone Hawthorne V, et al. Activation of the Akt/mammalian target of rapamycin/4EBP-1 pathway by ErbB2 overexpression predicts tumor progression in breast cancers. Clin Cancer Res. 2004;10:6779-6788.

53. Nahta R, Yuan LX, Du Y, Esteva FJ. Lapatinib induces apoptosis in trastuzumab-resistant breast cancer cells: effects on insulin-like growth factor I signaling. Mol Cancer Ther. 2007;6:667-674.

54. Clark AS, West K, Streicher S, Dennis PA. Constitutive and inducible Akt activity promotes resistance to chemotherapy, trastuzumab, or tamoxifen in breast cancer cells. Mol Cancer Ther. 2002;1:707-717.

55. She QB, Solit D, Basso A, Moasser MM. Resistance to gefitinib in PTEN-null HER-overexpressing tumor cells can be overcome through restoration of PTEN function or pharmacologic modulation of constitutive phosphatidylinositol 3'-kinase/Akt pathway signaling. Clin Cancer Res. 2003;9:4340-4346.

56. Bianco R, Shin I, Ritter CA, et al. Loss of PTEN/MMAC1/TEP in EGF receptor-expressing tumor cells counteracts the antitumor action of EGFR tyrosine kinase inhibitors. Oncogene. 2003;22:2812-2822.

57. Moasser MM, Basso A, Averbuch SD, Rosen N. The tyrosine kinase inhibitor ZD1839 ("Iressa") inhibits HER2-driven signaling and suppresses the growth of HER2-overexpressing tumor cells. Cancer Res. 2001;61:7184-7188.

58. Brognard J, Clark AS, Ni Y, Dennis PA. Akt/protein kinase B is constitutively active in non-small cell lung cancer cells and promotes cellular survival and resistance to chemotherapy and radiation. Cancer Res. 2001;61:3986-3997.

59. Tokunaga E, Kataoka A, Kimura Y, et al. The association between Akt activation and resistance to hormone therapy in metastatic breast cancer. Eur J Cancer. 2006;42:629-635.

60. Carpenter JT, Roche H, Campone M, et al. Randomized 3-arm, phase 2 study of temsirolimus (CCI-779) in combination with letrozole in postmenopausal women with locally advanced or metastatic breast cancer [abstract]. Proc Am Soc Clin Oncol. 2005;23:564. 
61. Tabernero J, Rojo F, Burris H, et al. A phase I study with tumor molecular pharmacodynamic (MPD) evaluation of dose and schedule of the oral mTOR-inhibitor everolimus (RAD001) in patients (pts) with advanced solid tumors [abstract]. Proc Am Soc Clin Oncol. 2005;23:3007.

62. Baselga J, Semiglazov V, van Dam P, et al. Phase II double-blind randomized trial of daily oral RAD001 (everolimus) plus letrozole (LET) or placebo $(\mathrm{P})$ plus LET as neoadjuvant therapy for ER+ breast cancer [abstract]. San Antonio Breast Cancer Symposium. 2007:2066.

63. Tsurutani J, Fukuoka J, Tsurutani H, et al. Evaluation of two phosphorylation sites improves the prognostic significance of Akt activation in non-small-cell lung cancer tumors. J Clin Oncol. 2006;24:306-314.

64. Tsurutani J, Steinberg SM, Ballas M, et al. Prognostic significance of clinical factors and Akt activation in patients with bronchioloalveolar carcinoma. Lung Cancer. 2007;55:115-121.

65. Tang JM, He QY, Guo RX, Chang XJ. Phosphorylated Akt 1 and loss of PTEN expression in non-small cell lung cancer confers poor prognosis. Lung Cancer. 2006;51:181-191.

66. Sordella R, Bell DW, Haber DA, Settleman J. Gefitinib-sensitizing EGFR mutations in lung cancer activate anti-apoptotic pathways. Science. 2004;305:1163-1167.

67. Cappuzzo F, Hirsch FR, Rossi E, et al. Epidermal growth factor receptor gene and protein and gefitinib sensitivity in non-small-cell lung cancer. J Natl Cancer Inst. 2005;97:643-655.

68. Han SW, Hwang PG, Chung DH, et al. Epidermal growth factor receptor (EGFR) downstream molecules as response predictive markers for gefitinib (Iressa, ZD1839) in chemotherapy-resistant non-small cell lung cancer. Int J Cancer. 2005;113:109-115.

69. Tracy S, Mukohara T, Hansen M, Meyerson M, Johnson BE, Jänne PA. Gefitinib induces apoptosis in the EGFRL858R non-small-cell lung cancer cell line H3255. Cancer Res. 2004;64:7241-7244.

70. Videtic GM, Stitt LW, Dar AR, et al. Continued cigarette smoking by patients receiving concurrent chemoradiotherapy for limited-stage small-cell lung cancer is associated with decreased survival. J Clin Oncol. 2003;21:1544-1549.

71. Carlisle DL, Liu X, Hopkins TM, Swick MC, Dhir R, Siegfried JM. Nicotine activates cell-signaling pathways through muscle-type and neuronal nicotinic acetylcholine receptors in non-small cell lung cancer cells. Pulm Pharmacol Ther. 2007;20:629-641.

72. Tsurutani J, Castillo SS, Brognard J, et al. Tobacco components stimulate Akt-dependent proliferation and NFkappaB-dependent survival in lung cancer cells. Carcinogenesis. 2005;26:1182-1195.

73. Jimeno A, Hidalgo M. Molecular biomarkers: their increasing role in the diagnosis, characterization, and therapy guidance in pancreatic cancer. Mol Cancer Ther. 2006;5:787-796.

74. Zhang Y, Banerjee S, Wang Z, et al. Antitumor activity of epidermal growth factor receptor-related protein is mediated by inactivation of ErbB receptors and nuclear factor-kappaB in pancreatic cancer. Cancer Res. 2006;66:1025-1032.

75. Wang Z, Sengupta R, Banerjee S, et al. Epidermal growth factor receptor-related protein inhibits cell growth and invasion in pancreatic cancer. Cancer Res. 2006;66:7653-7660.

76. Buck E, Eyzaguirre A, Brown E, et al. Rapamycin synergizes with the epidermal growth factor receptor inhibitor erlotinib in non-smallcell lung, pancreatic, colon, and breast tumors. Mol Cancer Ther. 2006;5:2676-2684.

77. Nelson EC, Evans CP, Mack PC, Devere-White RW, Lara PN. Inhibition of Akt pathways in the treatment of prostate cancer. Prostate Cancer Prostatic Dis. 2007;10:331-339.

78. Wang Y, Kreisberg JI, Ghosh PM. Cross-talk between the androgen receptor and the phosphatidylinositol 3-kinase/Akt pathway in prostate cancer. Curr Cancer Drug Targets. 2007;7:591-604.

79. Xu R, Qiu M, Han B. The prognostic impact of hypoxia-inducible factor- $1 \alpha$ and p-Akt expressions in gastric adenocarcinoma [abstract]. $J$ Clin Oncol. 2008;26(suppl):4560.

80. Oki E, Baba H, Tokunaga E, et al. Akt phosphorylation associates with $\mathrm{LOH}$ of PTEN and leads to chemoresistance for gastric cancer. Int $J$ Cancer. 2005;117:376-380.
81. Oki E, Kakeji Y, Tokunaga E, et al. Akt-mediated YB-1 phosphorylation induces resistance for chemotherapy of gastric cancer [abstract]. ASCO Annual Meeting Proceedings. J Clin Oncol. 2007;4554.

82. Murakami D, Tsujitani S, Osaki T, et al. Expression of phosphorylated Akt (pAkt) in gastric carcinoma predicts prognosis and efficacy of chemotherapy. Gastric Cancer. 2007;10:45-51.

83. D‘Errico A, Fiorentino M, Ponzetto A, et al. Liver hepatocyte growth factor does not always correlate with hepatocellular proliferation in human liver lesions: its specific receptor c-met does. Hepatology. 1996;24:60-64.

84. Suzuki A, Hayashida M, Kawano H, Sugimoto K, Nakano T, Shiraki K. Hepatocyte growth factor promotes cell survival from Fas-mediated cell death in hepatocellular carcinoma cells via Akt activation and Fas-death-inducing signaling complex suppression. Hepatology. 2000; 32(4 Pt 1):796-802.

85. Nakamura M, Nagano H, Sakon M, et al. Role of the Fas/FasL pathway in combination therapy with interferon-alpha and fluorouracil against hepatocellular carcinoma in vitro. J Hepatol. 2007;46:77-88.

86. Schiffer E, Housset C, Cacheux W, et al. Gefitinib, an EGFR inhibitor, prevents hepatocellular carcinoma development in the rat liver with cirrhosis. Hepatology. 2005;41:307-314.

87. Lund P, Schubert D, Niketeghad F, Schirmacher P. Autocrine inhibition of chemotherapy response in human liver tumor cells by insulin-like growth factor-II. Cancer Lett. 2004;206:85-96.

88. Desbois-Mouthon C, Cacheux W, Blivet-Van Eggelpoël MJ, et al. Impact of IGF-1R/EGFR cross-talks on hepatoma cell sensitivity to gefitinib. Int J Cancer. 2006;119:2557-2566.

89. Hjelmeland AB, Lattimore KP, Fee BE, et al. The combination of novel low molecular weight inhibitors of RAF (LBT613) and target of rapamycin (RAD001) decreases glioma proliferation and invasion. Mol Cancer Ther. 2007;6:2449-2457.

90. Sartelet H, Castain M, Fabre M, et al. Activation of the PI3K/Akt pathway in neuroblastoma. 2007 ASCO Annual Meeting. Abstract No. 9523.

91. Jiang BH, Liu LZ. Role of mTOR in anticancer drug resistance: perspectives for improved drug treatment. Drug Resist Updat. 2008; 11(3):63-76.

92. Johnston SR, Leary A, Martin LA, Smith IE, Dowsett M. Enhancing endocrine response with novel targeted therapies: why have the clinical trials to date failed to deliver on the preclinical promise? Cancer. 2008;112(3 Suppl):710-717.

93. Kolasa IK, Rembiszewska A, Felisiak A, et al. PIK3CA amplification associates with resistance to chemotherapy in ovarian cancer patients. Cancer Biol Ther. 2009;Jan 17, 8(1). [Epub ahead of print].

94. Guerreiro AS, Fattet S, Fischer B, et al. Targeting the PI3K p110alpha isoform inhibits medulloblastoma proliferation, chemoresistance, and migration. Clin Cancer Res. 2008;14(21):6761-6769.

95. Wolpin BM, Hezel AF, Abrams T, et al. Oral mTOR inhibitor everolimus in patients with gemcitabine-refractory metastatic pancreatic cancer. J Clin Oncol. 2009;27(2):193-198.

96. Ghayad SE, Bieche I, Vendrell JA, et al. mTOR inhibition reverses acquired endocrine therapy resistance of breast cancer cells at the cell proliferation and gene-expression levels. Cancer Sci. 2008;99(10):1992-2003.

97. Stauffer F, Garcia-Echeverirria C, Furet P. Biochemical, cellular, and in vivo profiling of a new PI3K inhibitor from the imidazoquinoline series. Los Angeles, CA: American Association for Cancer Research Annual Meeting 2007; Apr 14-18, 2007.

98. Hutson TE, Figlin RA. Experimental therapy for advanced renal cell carcinoma. Expert Opin Investig Drugs. 2008;17(11):1693-1702.

99. Yao J, Phan A, Chang D et al. Phase II study of RAD001 (everolimus) and depot octreotide (Sandostatin LAR) in patients with advanced low grade neuroendocrine carcinoma (LGNET) [abstract]. ASCO 2006 Annual Meeting Proceedings. J Clin Oncol. 2006;24(18 Suppl):4042.

100. LoPiccolo J, Granville CA, Gills JJ, Dennis PA. Targeting Akt in cancer therapy. Anticancer Drugs. 2007;18:861-874.

101. Qun Li. Recent progress in the discovery of Akt inhibitors as anticancer agents. Expert Opin Ther Patents. 2007;17:1077-1130.

102. Mollinedo F. Antitumour ether lipids: proapoptotic agents with multiple therapeutic indications. Expert Opin Ther Patents. 2007;17:385-405. 
103. Allerton JP, Ebrahimi B, Schreeder MT, et al. Phase I report from a multicenter trial of perifosine (PERI) + sunitinib (SUT) in patients with advanced cancers including renal cell carcinoma (RCC). 2008 ASCO Annual Meeting Abstract No. 14565.

104. Mohapatra S, Chu B, Zhao X, et al. Combination inhibition of Cdk9 and Akt induces apoptosis of metastatic prostate cancer cells [abstract]. Los Angeles, CA: Annual Meeting of American Association for Cancer Research; 2007. 5399.

105. Kumar R, Rhodes N, Knick VB, et al. GSK690693, a pan-Akt kinase inhibitor has potent anti-tumor activity and shows additive effect with lapatinib [abstract]. Los Angeles, CA: Annual Meeting of American Association for Cancer Research; 2007. 279.

106. Rhodes N, Knick VB, McConnell R, et al. GSK690693, a pan-Akt kinase inhibitor with potent pharmacodynamic and antitumor activity in vivo [abstract]. Los Angeles, CA: Annual Meeting of American Association for Cancer Research; 2007. 277.

107. Dummler B, Hemmings BA. Physiological roles of PKB/Akt isoforms in development and disease. Biochem Soc Trans. 2007;35:231-235.

108. Donald A, McHardy T, Rowlands MG, et al. Rapid evolution of 6-phenylpurine inhibitors of protein kinase B through structure-based design. J Med Chem. 2007;50:2289-2292.

109. Sun SY, Rosenberg LM, Wang X, et al. Activation of Akt and eIF4E survival pathways by rapamycin-mediated mammalian target of rapamycin inhibition. Cancer Res. 2005;65:7052-7058.

110. Shi $Y$, Yan H, Frost $P$, et al. Mammalian target of rapamycin inhibitors activate the Akt kinase in multiple myeloma cells by up-regulating the insulin-like growth factor receptor/insulin receptor substrate-1/phosphatidylinositol 3-kinase cascade. Mol Cancer Ther. 2005;4:1533-1540.

111. Luo Y, Smith RA, Guan R, et al. Pseudosubstrate peptides inhibit Akt and induce cell growth inhibition. Biochemistry. 2004;43:1254-1263.

112. Zhu GD, Gandhi VB, Gong J, et al. Syntheses of potent, selective, and orally bioavailable indazole-pyridine series of protein kinase B/Akt inhibitors with reduced hypotension. $J$ Med Chem. 2007;50:2990-3003.

113. Marshall J, Posey J, Hwang S, et al. A phase I trial of RX-0201 (Akt anti-sense) in patients with an advanced cancer. 2007 ASCO Annual Meeting. Abstract No. 3564.

114. David O, Jett J, LeBeau H, Dy G, Hughes J, Friedman M, Brody AR. Phospho-Akt overexpression in non-small cell lung cancer confers significant stage-independent survival disadvantage. Clin Cancer Res. 2004;15;10(20):6865-6871.

115. Soria JC, Lee HY, Lee JI, Wang L, Issa JP, Kemp BL, et al. Lack of PTEN expression in non-small cell lung cancer could be related to promoter methylation. Clin Cancer Res. 2002;May, 8(5):1178-1184.

116. Steelman LS, Stadelman KM, Chappell WH, Horn S, Bäsecke J, Cervello M, et al. Akt as a therapeutic target in cancer. Expert Opin Ther Targets. 2008;12(9):1139-1165. Review.

117. Horiguchi A, Oya M, Uchida A, Marumo K, Murai M. Elevated Akt activation and its impact on clinicopathological features of renal cell carcinoma. J Urol. 2003;169:710-713

118. Shin Lee J, Seok Kim H, Bok Kim Y, Cheol Lee M, Soo Park C. Expression of PTEN in renal cell carcinoma and its relation to tumor behavior and growth. J Surg Oncol. 2003;84:166-172.

119. Bjornsson J, Short MP, Kwiatkowski DJ, Henske EP. Tuberous sclerosis-associated renal cell carcinoma. Clinical, pathological, and genetic features. Am J Pathol. 1996;149:1201-1208.
120. Zhou X, et al. Activation of the Akt/Mammalian Target of Rapamycin/4E-BP1 Pathway by ErbB2 Overexpression Predicts Tumor Progression in Breast Cancers Clin Cancer Res. 2004;10:6779-6788.

121. Bacus SS, Altomare DA, Lyass L, Chin DM, Farrell MP, Gurova K, et al. Akt2 is frequently upregulated in HER-2/neu-positive breast cancers and may contribute to tumor aggressiveness by enhancing cell survival. Oncogene. 2002; May 16;21(22):3532-3540.

122. Li J, Yen C, Liaw D, Podsypanina K, Bose S, Wang SI, Puc J, et al. PTEN, a putative protein tyrosine phosphatase gene mutated in human brain, breast, and prostate cancer. Science. 1997;28,275(5308):1943-1947.

123. Saal LH, Holm K, Maurer M, Memeo L, Su T, Wang X, et al. PIK3CA mutations correlate with hormone receptors, node metastasis, and ERBB2, and are mutually exclusive with PTEN loss in human breast carcinoma. Cancer Res. 2005;65:2554-2559.

124. Francalanci P, Diomedi-Camassei F, Purificato C, Santorelli FM, Giannotti A, Dominici C, et al. Malignant pancreatic endocrine tumor in a child with tuberous sclerosis. Am J Surg Pathol. 2003;Oct, 27(10): 1386-1389.

125. Steelman LS, Stadelman KM, Chappell WH, Horn S, Bäsecke J, Cervello M, et al. Akt as a therapeutic target in cancer. Expert Opin Ther Targets. 2008;12(9):1139-1165. Review.

126. McCall P, Witton CJ, Grimsley S, Nielsen KV, Edwards J. Is PTEN loss associated with clinical outcome measures in human prostate cancer? Br J Cancer. 2008;99(8):1296-1301.

127. Itoh $\mathrm{N}$, Semba $\mathrm{S}$, Ito $\mathrm{M}$, Takeda $\mathrm{H}$, Kawata $\mathrm{S}$, Yamakawa $\mathrm{M}$. Phosphorylation of Akt/PKB is required for suppression of cancer cell apoptosis and tumor progression in human colorectal carcinoma. Cancer. 2002;Jun 15;94(12):3127-3134.

128. Frattini M, Signoroni S, Pilotti S, Bertario L, Benvenuti S, Zanon C, et al. Phosphatase protein homologue to tensin expression and phosphatidylinositol-3 phosphate kinase mutations in colorectal cancer. Cancer Res. 2005;65(23):11227.

129. Samuels Y, Velculescu VE. Oncogenic mutations of PIK3CA in human cancers. Cell Cycle. 2004;Oct, 3(10):1221-1224.

130. Tabernero J, Rojo F, Burris H, et al. A phase I study with tumor molecular pharmacodynamic (MPD) evaluation of dose and schedule of the oral mTOR-inhibitor everolimus (RAD001) in patients (pts) with advanced solid tumors. Proc Am Soc Clin Oncol. 2005;23. Abstr 3007.

131. Cappuzzo F, Hirsch FR, Rossi E, et al. Epidermal growth factor receptor gene and protein and gefitinib sensitivity in non-small-cell lung cancer. J Natl Cancer Inst. 2005;97:643-655.

132. Han SW, Hwang PG, Chung DH, et al. Epidermal growth factor receptor (EGFR) downstream molecules as response predictive markers for gefitinib (Iressa, ZD1839) in chemotherapy-resistant non-small cell lung cancer. Int $J$ Cancer. 2005;113:109-115.

133. Tracy S, Mukohara T, Hansen M, Meyerson M, Johnson BE, Jänne PA. Gefitinib induces apoptosis in the EGFRL858R non-small-cell lung cancer cell line H3255. Cancer Res. 2004;64:7241-7244.

134. Wang Y, Kreisberg JI, Ghosh PM. Cross-talk between the androgen receptor and the phosphatidylinositol 3-kinase/Akt pathway in prostate cancer. Curr Cancer Drug Targets. 2007;7:591-604. Review.

135. Nelson EC, Evans CP, Mack PC, Devere-White RW, Lara PN. Inhibition of Akt pathways in the treatment of prostate cancer. Prostate Cancer and Prostatic Diseases. 2007;1-9.
OncoTargets and Therapy

\section{Publish your work in this journal}

OncoTargets and Therapy is an international, peer-reviewed, open access journal focusing on the pathological basis of all cancers, potential targets for therapy and treatment protocols employed to improve the management of cancer patients. The journal also focuses on the impact of management programs and new therapeutic agents and protocols on

\section{Dovepress}

patient perspectives such as quality of life, adherence and satisfaction. The manuscript management system is completely online and includes a very quick and fair peer-review system, which is all easy to use. Visit http://www.dovepress.com/testimonials.php to read real quotes from published authors. 